\title{
Proteções solares no Regulamento brasileiro de Eficiência Energética de Edifícios Comerciais, de Serviços e Públicos
}

\author{
Solar protections in the Brazilian Regulation on the \\ Energy Efficiency of Commercial, Service and Public \\ Buildings
}

\section{lara Gonçalves dos Santos \\ Roberta Vieira Gonçalves de Souza}

\section{Resumo}

lara Gonçalves dos Santos Escola de Arquitetura Universidade Federal de Minas Gerais Rua Paraíba, 697, Sala 319, Funcionários

Belo Horizonte - MG -Brasil CEP $30130-140$ Tel.: (31) 3269-1823 E-mail: iaragds@yahoo.com.br

Roberta Vieira Gonçalves de Souza

Departamento de Tecnologia da Arquitetura e do Urbanismo Universidade Federal de Minas Gerais

E-mail: robertavgs2@gmail.com

Recebido em 10/10/11

Aceito em 06/03/12

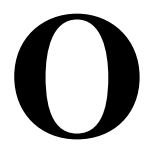

Regulamento Técnico da Qualidade para Eficiência Energética de Edifícios Comerciais, de Serviços e Públicos (RTQ-C) é a referência brasileira para avaliação de desempenho energético de edifícios. $\mathrm{O}$ presente trabalho enfoca a influência de proteções solares no desempenho de edifícios a partir deste documento. Para isto, o RTQ-C é aplicado a um projeto de edificação que não possui tais dispositivos. Proteções são então aplicadas ao edifício e o desempenho energético é calculado pelo método prescritivo do RTQ. Por simulação computacional, as mesmas proteções são inseridas em um ambiente-padrão do prédio e obtêm-se dados de consumo de energia total e com iluminação. Ao longo do estudo, discute-se os resultados obtidos pelo método prescritivo e por simulação com o objetivo de levantar considerações sobre a metodologia de análise de envoltória pelo Regulamento. Paralelamente, buscou-se avaliar o desempenho de brises e de prateleiras de luz dimensionados pelo método da Temperatura Neutra. Os principais resultados reforçam a importância de se considerar a geometria e a orientação solar dos dispositivos no desempenho, fatores que não são avaliados pelo RTQ-C prescritivo.

Palavras-chave: Código de energia em edifícios. Simulação de desempenho de edifício. Dispositivo de proteção solar.

\section{Abstract}

The Technical Quality Regulation on the Energy Efficiency of Commercial, Service and Public Buildings (RTQ-C) is the Brazilian reference for evaluating the energy performance of buildings. This study focuses on the influence of solar protection devices in building consumption based on this code. A building without solar devices is analysed under the prescriptive method of RTQ-C. Overhangs and lightshelves are designed for the building and the performance under RTQ-C is recalculated. Then, the same devices are applied to a room in the building. The total energy consumption of the room with and without solar devices is obtained through computer simulation. The results of this process are the basis for a discussion about the performance evaluation criterion of the prescriptive method of RTQ-C. The main results reinforce that the geometry and solar orientation of a device must be considered, although the prescriptive RTQ-C does not consider those aspects.

Keywords: Building energy code. Building performance simulation. Solar protection device. 


\section{Introdução}

No Brasil entrou em vigor em 2009 o "Regulamento Técnico da Qualidade para Eficiência Energética de Edifícios Comerciais, de Serviços e Públicos”, aqui abreviado como RTQC. A primeira revisão do documento ocorreu em 2010 e permanece em vigor. O documento permite a avaliação do edifício por um método prescritivo ou por simulação computacional, classificando o desempenho dele e de seus sistemas (envoltória, iluminação e ar condicionado) de nível "A”, mais eficiente, a "E”, menos eficiente (BRASIL, 2010a).

No RTQ-C prescritivo, a influência das proteções solares no consumo é relacionada a apenas uma característica: aos ângulos que formam com as aberturas. Não são considerados geometrias, tipos de acabamento, refletividade da superfície, entre outros fatores relevantes para o desempenho dos dispositivos.

Nesse contexto, este trabalho discute como o método prescritivo aborda o efeito de proteções solares no desempenho energético de envoltórias a partir de um estudo de caso. São avaliados brises e prateleiras de luz, tanto pelo método prescritivo do Regulamento quanto por simulação computacional. Com isso são levantadas algumas considerações sobre a metodologia de análise desses dispositivos presentes no Regulamento brasileiro.

No Regulamento, a avaliação da envoltória de um edifício baseia-se em dois fatores: no cumprimento de itens prescritivos e no resultado do chamado Indicador de Consumo da Envoltória ( $\mathrm{IC}_{\mathrm{env}}$ ). Esse indicador resulta da combinação de características do edifício numa equação, a qual varia para cada Zona Bioclimática brasileira (ABNT, 2005) e conforme a área de projeção do edifício. Todas as equações foram geradas a partir de estudos de consumo energético em protótipos de edifícios simulados por computador. O exemplo abaixo apresenta a equação utilizada neste trabalho, válida para edifícios localizados na Zona Bioclimática 3 e cuja área de projeção é superior a $500 \mathrm{~m}^{2}$ (BRASIL, 2010a):

$\mathrm{IC}_{\text {env }}=-14,14 \cdot \mathrm{FA}-113,94 \cdot \mathrm{FF}+50,82 \cdot \mathrm{PAFt}+$ 4,86.FS - 0,32.AVS + 0,26.AHS - 35,75 FF 0,54.PAFt.AHS + 277,98

Eq. 1

Onde:

ICenv: indicador de consumo da envoltória (adimensional);

FA: fator altura (adimensional) $=\mathrm{A}_{\mathrm{pe}} / \mathrm{A}_{\mathrm{tot}}$;

FF: fator de forma (adimensional) $=\mathrm{A}_{\text {env }} / \mathrm{V}_{\text {tot }}$;

$\mathrm{A}_{\mathrm{pe}}$ : área de projeção do edifício $\left(\mathrm{m}^{2}\right)$;

$\mathrm{A}_{\text {tot }}$ : área total de piso $\left(\mathrm{m}^{2}\right)$;

$\mathrm{A}_{\text {env }}$ : área da envoltória $\left(\mathrm{m}^{2}\right)$;

$\mathrm{V}_{\text {tot }}$ : volume total da edificação $\left(\mathrm{m}^{3}\right)$;

$\mathrm{PAF}_{\mathrm{T}}$ : percentual de abertura na fachada total (\%);

FS: fator solar médio dos vidros (adimensional);

AVS: ângulo vertical de sombreamento, relativo a proteções solares horizontais (adimensional); e

AHS: ângulo horizontal de sombreamento, relativo a proteções solares verticais (adimensional).

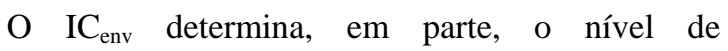
classificação da envoltória de "A" a "E”. Seu valor é enquadrado em uma escala numérica, cujos intervalos são calculados conforme limites de consumo admissíveis para cada nível (Tabela 1 e Equação 2, em nota da Tabela). O limite máximo é encontrado aumentando-se a área de aberturas do edifício e reduzindo-se o fator solar dos vidros (retoma-se Eq.1 com PAFt = 0,60; FS = 0,61). Para o limite mínimo, o percentual de área de abertura é reduzido e é usado fator solar típico de vidros comuns de $3 \mathrm{~mm}$ de espessura (faz-se PAFt $=0,05 ; \mathrm{FS}=0,87$ ). Nessa escala, as proteções solares são eliminadas (faz-se AVS=0; AHS=0).

Tabela 1 - Intervalos dos níveis de eficiência para classificação final da envoltória (BRASIL, 2010a)

\begin{tabular}{c|l|l|l|l|c}
\hline \multicolumn{1}{c|}{ Nível } & \multicolumn{1}{c|}{ A } & \multicolumn{1}{c|}{ B } & \multicolumn{1}{c}{ C } & \multicolumn{1}{c}{ D } & E \\
\hline Limite mín. & - & ICmáxD - 3i $+0,01$ & ICmáxD - 2i + 0,01 & ICmáxD - i + 0,01 & ICmáxD + 0,01 \\
\hline Limite máx. & ICmáxD - 3i & ICmáxD - 2i & ICmáxD - i & ICmáxD & - \\
\hline
\end{tabular}

Nota: onde:

$\mathrm{i}=\left(I \mathrm{C}_{\max \mathrm{D}} \cdot \mathrm{IC} \mathrm{C}_{\min }\right) / 4$

Eq. 2

$\mathrm{i}$ : intervalo para cálculo dos níveis de eficiência;

Limite mín: limites mínimos dos indicadores de consumo conforme a eficiência desejada;

Limite máx: limites máximos dos indicadores de consumo conforme a eficiência desejada;

ICmaxD: limite máximo do indicador de consumo para a volumetria obter classificação D; e

ICmin: limite mínimo do indicador de consumo para a volumetria. 
Os parâmetros AVS e AHS da equação de $\mathrm{IC}_{\text {env }}$ ponderam a influência das proteções solares no consumo do edifício. Resultam da média dos ângulos formados entre o plano do vidro e a extremidade da proteção horizontal (AVS) ou vertical (AHS) de todas as aberturas. Pelo Regulamento, o ângulo máximo que pode ser aplicado na equação é $45^{\circ}$ para “[...] evitar o uso de proteções excessivas que possam prejudicar a penetração da luz natural difusa nos ambientes internos[...]” (BRASIL, 2008b, p. 18). Para algumas zonas, o ângulo máximo é ainda mais restritivo. Contudo, o documento adverte que

\section{[...] esta exigência não determina o dimensionamento das proteções solares. Elas devem ser projetadas para evitar o sobreaquecimento dos ambientes internos considerando as necessidades de sombreamento específicas do edifício, as condições sazonais do clima local (trajetória solar e temperaturas) $e$ a orientação de cada fachada [...] (BRASIL, 2010a, p. 31).}

Segundo Gutierrez e Labaki (2003), a efetividade da proteção solar sobre a envoltória depende da distância relativa à fachada, o que influi na transmissão de calor, do coeficiente de reflexão e absorção do material relativo à radiação solar, e da geometria do elemento, a qual influi na capacidade de sombreamento em função da trajetória solar. Entretanto, nessa versão prescritiva do RTQ-C, somente o ângulo do dispositivo pode ser considerado. Além disso, as tipologias de proteção solar que podem ser contabilizadas restringem-se àquelas contínuas em contato direto com a fachada, às vazadas (tipo pergolado ou laminadas), cujas aletas estão paralelas à abertura e sem grande distanciamento entre si, às proteções paralelas externas à abertura (pórticos, chapas perfuradas, etc.), que estão fisicamente conectadas ao edifício e distanciadas do plano de vidro a até uma altura equivalente à do vão. E não há diferenciação de proteções móveis, as quais devem ser avaliadas como fixas considerando seu ângulo máximo de sombreamento.

Pesquisa apresentada pelo Ministério de Minas e Energia (MME) relata que 15,7\% dos edifícios comerciais brasileiros utilizam algum tipo de proteção externa. Toldos e venezianas são os mais usados; juntos não chegam a $10 \%$ da amostra avaliada. Brises correspondem a 2,8\%, prateleiras de luz, a 0,3\%. O Ministério reconhece que a ocorrência é baixa, havendo espaço para incentivo de uso desses dispositivos através de programa de eficiência energética (BRASIL, 2008a).
Diversos trabalhos no Brasil investigaram a redução no consumo de energia elétrica anual de edifícios com a utilização de brises, através de simulação computacional. Como exemplo, Signor (1999) desenvolveu equações para caracterizar o consumo de edifícios de escritórios para diversas capitais brasileiras. A partir dos dados apresentados, pode-se inferir que a redução por brises horizontais ficou entre 3\% e 14\%. Santana (2006) inseriu brises verticais e horizontais com um ângulo máximo de $45^{\circ}$ em um caso-base de escritório de Florianópolis, encontrando até 11,6\% de diminuição. Carlo (2008) variou características construtivas de protótipos de edificações comerciais através do software EnergyPlus, identificando que as proteções solares estão atrás apenas do percentual de área de janela na fachada como medida de conservação de energia (MCE), com maior potencial de proporcionar resultados vantajosos.

Sobre as prateleiras de luz, foram feitos estudos de desempenho térmico e luminoso. Macedo e Pereira (2003) usaram modelos em escala sob o céu real de Florianópolis (latitude $27^{\circ} \mathrm{S}$ ) e comprovaram que a prateleira de luz espelhada promoveu melhor distribuição interna da luz e menor ganho de calor em relação à abertura sem proteção. Santos e Bastos (2008) analisaram por software um escritório de planta livre no Rio de Janeiro (latitude $22^{\circ} \mathrm{S}$ ) e concluíram que prateleiras de luz usadas como proteção solar externa, com vidros de baixa transmissão visível até o nível dos olhos do usuário e maior transmissão no alto da janela, melhoram a distribuição da luz natural sem afetar o conforto visual do ocupante. Diferenciando o desempenho por orientação solar, concluíram que a prateleira a sul foi menos eficiente do que a norte.

Aspecto importante das proteções solares é seu dimensionamento correto. Pereira e Souza (2008) propõem um método orientado ao conforto térmico, que correlaciona os seguintes fatores: o tamanho da abertura em relação ao piso, o uso do edifício, a radiação solar incidente na fachada e, por fim, a temperatura na qual uma população local em atividade sedentária está aclimatada e sente-se confortável. Esta é denominada Temperatura Neutra $\left(T_{n}\right)$, a qual depende da temperatura média mensal do ar $\left(\mathrm{T}_{\mathrm{e}}\right)$ :

$\mathrm{T}_{\mathrm{n}}=0,31 \mathrm{~T}_{\mathrm{e}}+17,6^{\circ} \mathrm{C}$

Eq. 3

O ângulo da proteção é obtido por transferidor auxiliar sobreposto a um diagrama de radiação incidente em plano vertical e a uma carta solar para a latitude local. Essa carta é previamente colorida segundo faixas de temperatura aceitáveis segundo o conceito da Temperatura Neutra, a 
partir de dados de Normais Climatológicas (BRASIL, 1992).

A seguir apresenta-se como exemplo a tabela temperatura horária média mensal para a cidade de Belo Horizonte, colorida conforme os limites de Temperatura Neutra (Figura 1). Essa identificação horária de cores é adaptada para a carta solar (Figura 2), sobre a qual é possível determinar os ângulos de proteção desejáveis para um ambiente conforme a temperatura externa.

Esse método de dimensionamento por Temperatura Neutra foi desenvolvido inicialmente no Laboratório de Conforto Ambiental da Escola de Arquitetura da Universidade Federal de Minas
Gerais. Posteriormente, foi incorporado ao primeiro regulamento brasileiro aplicável a edifícios residenciais (BRASIL, 2010b). Nesse documento para habitações encontram-se informações mais detalhadas sobre o dimensionamento de proteções solares por esse método.

É provável que tal método seja introduzido também no Regulamento para Edifícios Comerciais, Públicos e de Serviços. O tema está sob avaliação, pois podem ser necessárias adaptações no método para que não haja conflito entre ele e a equação do método prescritivo, a qual já incorpora ângulos de sombreamento.

\begin{tabular}{|c|c|c|c|c|c|c|c|c|c|c|c|c|}
\hline Tn-8 & 16,8 & 16,9 & 16,8 & 16,2 & 15,8 & 15,4 & 15,3 & 15,6 & 16,2 & 16,5 & 16,6 & 16,6 \\
\hline & 17,8 & 17.9 & 17.8 & 17.2 & & & & & 17,2 & 11. & 17. & \\
\hline $\mathrm{Tn}+2$ & 26,8 & 26,9 & 26,8 & 26,2 & 25,8 & 25,4 & 25,3 & 25,6 & 26,2 & 26,5 & 26,6 & 26,57 \\
\hline \multirow[t]{2}{*}{$\mathrm{Tn}+4$} & 28,8 & 28,9 & 28,8 & 28,2 & 27,8 & 27,4 & 27,3 & 27,6 & 28,2 & 28,5 & 28,6 & 28,6 \\
\hline & JAN & FEV & MAR & ABR & MAIO & JUN & JUL & AGO & SET & OUT & NOV & DEZ \\
\hline $06: 00$ & 18,8 & 19,0 & 18,80 & 17,3 & 15,0 & 13,4 & 13,1 & 14,4 & 16,20 & 17,50 & 18,2 & 18,4 \\
\hline 09:00 & 22,8 & 23,2 & 23,0 & 21,7 & 19,7 & 18,4 & 18,0 & 19,60 & 20,9 & 21,9 & 22,2 & 22,2 \\
\hline $10: 00$ & 24,3 & 24,8 & 24,6 & 23,3 & 21,5 & 20,2 & 19,9 & 21,5 & 22,7 & 23,5 & 23,7 & 23,7 \\
\hline $11: 00$ & 25,6 & 26,1 & 25,9 & 24,6 & 22,9 & 21,8 & 21,4 & 23,1 & 24,1 & 24,8 & 24,9 & 24,8 \\
\hline $12: 00$ & 26,8 & 27,3 & 27,1 & 26,0 & 24,4 & 23,3 & 22,9 & 24,7 & 25,6 & 26,2 & 26,1 & 26,0 \\
\hline $13: 00$ & 27,2 & 27,7 & 27,5 & 26,4 & 24,79 & 23,7 & 23,34 & 25,2 & 26,0 & 26,6 & 26,5 & 26,3 \\
\hline $14: 00$ & 28,0 & 28,6 & 28,4 & 27,25 & 25,7 & 24,7 & 24,31 & 26,2 & 26,9 & 27,4 & 27,3 & 27,1 \\
\hline
\end{tabular}

Figura 1 - Tabela de temperatura horária média mensal para a cidade de Belo Horizonte

Fonte: Brasil (2010b).

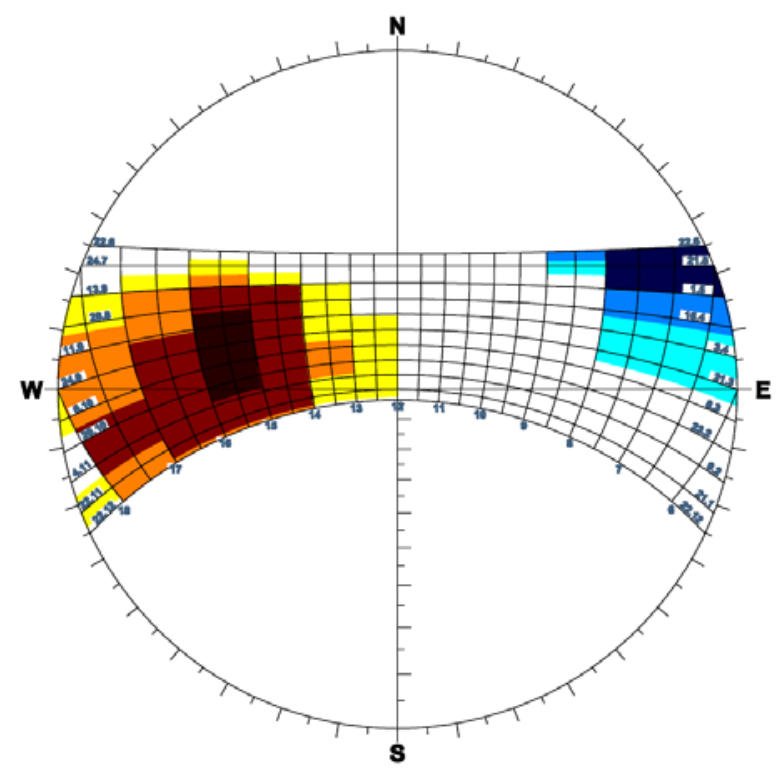

Figura 2 - Carta solar com cores de temperatura para Belo Horizonte

Fonte: adaptada de Brasil (2010b). 


\section{Método}

Embora não nesta ordem, a metodologia deste estudo organiza-se sob a seguinte estrutura:

(a) análise paramétrica da equação de ICenv para avaliar como ela considera a influência de proteções solares quaisquer no consumo de um edifício real;

(b) dimensionamento de proteções consideradas ideais para o edifício segundo:

- a equação de ICenv do RTQ-C; e

- o método da Temperatura Neutra $\left(\mathrm{T}_{\mathrm{n}}\right)$.

(c) avaliação do efeito dessas proteções no desempenho energético através de:

- resultado da equação de ICenv e classificação geral da envoltória pelo RTQ-C; e

- simulação computacional de um ambiente padrão do edifício nos quais as proteções foram aplicadas. São avaliados dados de consumo energético total, consumo com iluminação, ganho de calor através da fachada e do vidro, contemplando variações na geometria da proteção e no tipo de vidro aplicado na abertura.

(d) avaliação crítica comparativa entre os dois métodos, tanto pela equação de RTQ-C quanto por simulação computacional.

\section{Detalhamento do método}

Como estudo de caso, foi escolhido um edifício sujeito ao RTQ-C e cujo projeto original não prevê proteções sobre as aberturas. E, nesse edifício, selecionou-se um ambiente representativo em termos de consumo cuja abertura serviu de referência para o dimensionamento de proteções pelo método da Temperatura Neutra.

Foi escolhido o projeto do edifício-sede do Tribunal de Justiça do Estado de Minas Gerais (TJMG, Figura 3). O prédio será localizado na área

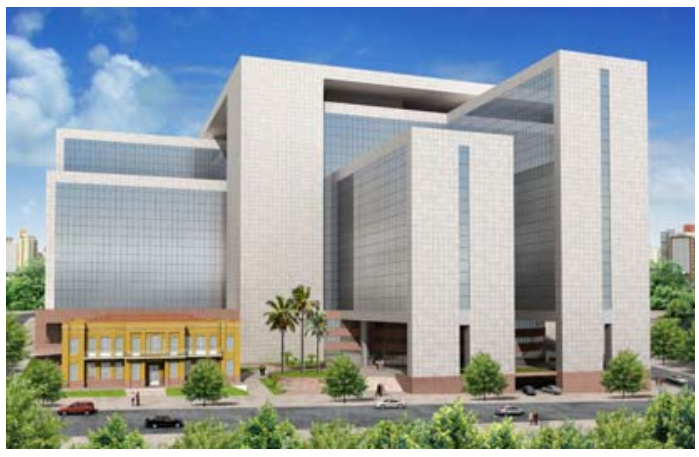

(a) urbana central da cidade de Belo Horizonte (195's e 4356'O, Zona Bioclimática 3). Projetado com área total de 136.647,36 m², possui duas torres externas de onze pavimentos e duas torres internas de sete pavimentos cada.

O ambiente de referência é denominado gabinete. Possui 29,5 m², projetado para ser um escritório. Repete-se no edifício em quatro orientações solares, totalizando 12.093,00 $\mathrm{m}^{2}$. Representa cerca de $17,5 \%$ da área útil do edifício e cerca de 9\% da área total do prédio. Portanto, análises de seu consumo podem ser ampliadas a parte significativa da edificação. Como equipamentos, possui seis luminárias para duas lâmpadas fluorescentes de $28 \mathrm{~W} / 220 \mathrm{~V}$, com reatores eletrônicos, com fileira de luminárias próximo à janela com acionamento independente. A climatização é feita por fancoletes apenas para resfriamento, com condições internas mantidas a $24{ }^{\circ} \mathrm{C}$ (TBS), $\pm 2{ }^{\circ} \mathrm{C}$, e umidade relativa de $50 \%$. As maiores dimensões internas do ambiente são 3,83 $\mathrm{m} \times 8,13 \mathrm{~m}$. O gabinete possui pé-direito total de 4,02 m, sendo 2,75 $\mathrm{m}$ do piso elevado ao forro. As refletâncias de paredes e forro são consideradas de $90 \%$, e do piso, de $30 \%$. Há uma única abertura para ao exterior, de 3,83 m x 1,55 m / 1,05 m. A Figura 4 apresenta a planta do pavimento-tipo e destaca um exemplo desse ambiente padrão com leiaute interno e luminárias.

Escolhido o edifício, aplicou-se a equação de ICenv para obter seu nível de classificação da envoltória pelo método prescritivo do RTQ-C (Equações 1 e 2).

Com o objetivo de avaliar-se a influência das proteções na classificação final de desempenho da envoltória, fez-se um estudo do comportamento da equação de indicador de consumo em relação às características desse edifício. Para isso, baseandose em trabalho semelhante de Carlo (2008), variaram-se apenas dados de AVS e AHS na Equação 1.

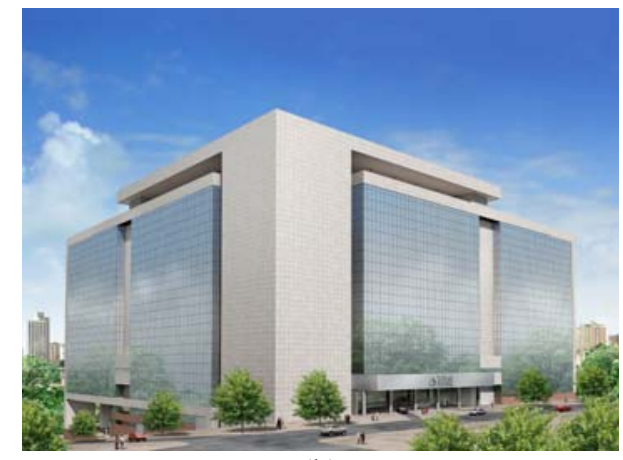

(b)

Figura 3 - Perspectivas eletrônicas frontal e posterior do edifício

Fonte: arquivo do TJMG/IDEAL (INSTITUTO..., 2009). 


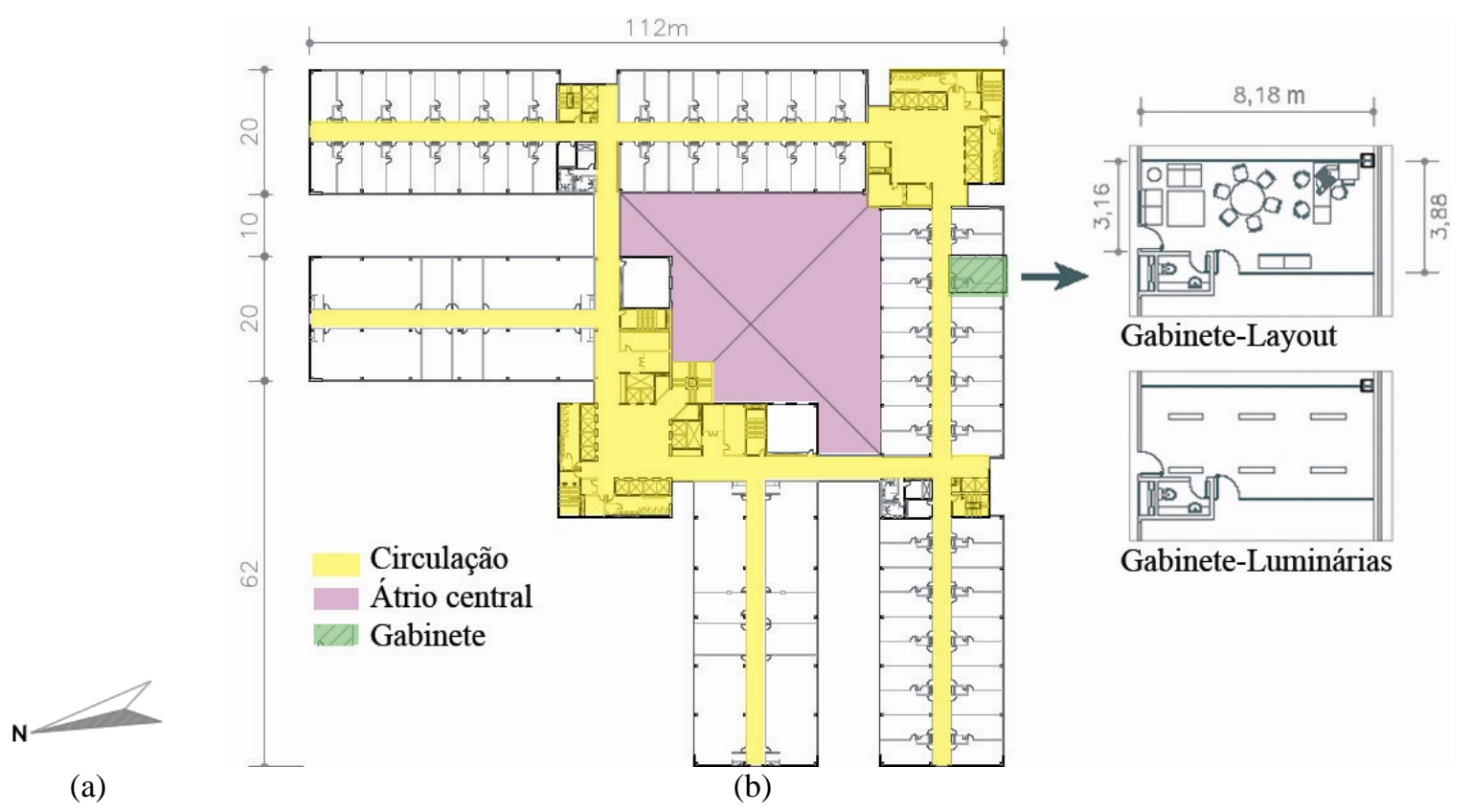

Figura 4 - (a) Planta do pavimento-tipo mostrando o ambiente de análise repetido ao longo das torres externas; e (b) Planta do ambiente com leiaute e, abaixo, demonstrando a distribuição das luminárias Nota: plantas sem escala, medidas em metros.

Fonte: arquivo do TJMG/ IDEAL (INSTITUTO..., 2009).

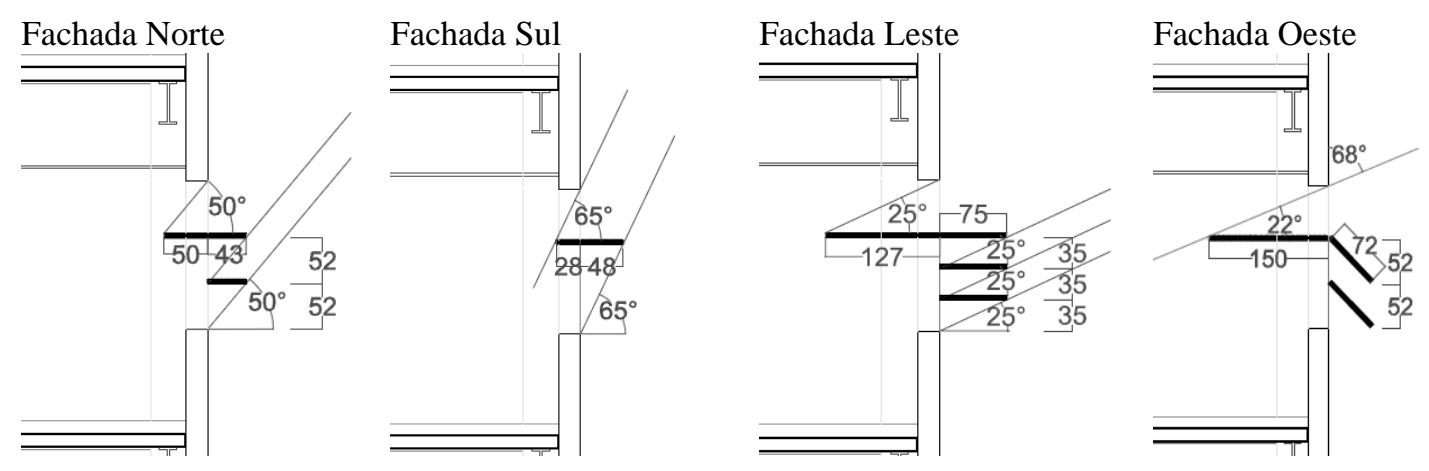

Figura 5 - Corte do ambiente apresentando as prateleiras dimensionadas pelo método da Temperatura Neutra, com respectivos ângulos de sombreamento (em graus) e dimensões (em cm)

A partir dessa análise, identificou-se a combinação de AVS e AHS que produz o menor ICenv para o edifício. Ou seja, quais ângulos de proteções solares contribuiriam para a redução máxima no consumo de energia do TJMG, conforme os critérios do RTQ-C. Com esses ângulos determinaram-se dois brises horizontais, nomeados RTQ e RTQ-2 (Figura 6). Ambos oferecem a mesma proteção contra a radiação solar direta. Entretanto, RTQ é uma lâmina única e RTQ-2 possui duas lâminas paralelas. Por simulação, esses brises foram aplicados ao ambiente padrão para investigar o efeito no consumo de energia, que é provocado por geometrias diferentes advindas de um mesmo conjunto de ângulos. Como o Regulamento não estabelece distinção de critérios para as proteções solares dependendo da orientação da fachada na equação de ICenv, o mesmo raciocínio foi aplicado no estudo dessas proteções por simulação: repetem-se sem alteração em todas as orientações.

Em seguida, definiram-se ângulos de proteções horizontais pelo método da Temperatura Neutra $\left(\mathrm{T}_{\mathrm{n}}\right)$ para a janela do ambiente de referência.

Tomou-se a variação da orientação dessa abertura para norte, sul, leste e oeste, ou seja, considerandose apenas os pontos cardeais, conforme demanda o RTQ-C prescritivo. Novo ICenv foi calculado considerando-se as proteções estendidas sobre as fachadas correspondentes. Para a etapa de simulação, com os ângulos obtidos por $T_{n}$, dimensionaram-se brises e prateleiras de luz (Figura 5), com o objetivo de avaliar o 
desempenho desses dois dispositivos e complementar $\mathrm{o}$ estudo de geometrias. $\mathrm{Na}$ simulação das prateleiras, testaram-se três diferentes vidros da abertura (Tabela 2) para avaliar o efeito deles sobre o consumo.

Como mostrado na Figura 5, para a simulação de todas as proteções foram gerados vários modelos computacionais do ambiente:

(a) um para o brise RTQ;

(b) outro para brise RTQ-2;

(c) quatro de brises por $T_{n}$, sendo um para cada orientação solar; e

(d) também quatro para prateleiras por $T_{n}$, cujos vidros foram alterados três vezes.

As proteções foram aplicadas a um modelo original sem proteções. O software EnergyPlus com arquivo climático da cidade em formato
TMY3 foi utilizado. Os padrões de uso, bem como as cargas de equipamentos, de iluminação e de ocupação foram inseridos conforme características de projeto: ambiente em funcionamento ao longo do ano durante os dias úteis, entre $9 \mathrm{~h}$ e $18 \mathrm{~h}$, contendo equipamentos para atividade de escritório (computador e impressora, basicamente), iluminado por luminárias com potência de $62 \mathrm{~W}$ cada e ocupado por uma pessoa. Para estudo do potencial de aproveitamento da iluminação natural, foram posicionados sensores internos em cada modelo, com regulagem contínua. O nível mínimo de iluminância foi estabelecido em 300 lux, a partir da norma brasileira NBR-5413 (ABNT, 1992). O sistema de ar condicionado é por expansão indireta com fancoletes, funcionando apenas para resfriamento do ambiente, com temperatura mantida a $24{ }^{\circ} \mathrm{C}$ no horário de $8 \mathrm{~h}$ às 18h. A infiltração do ar através das aberturas foi anulada.

Tabela 2 - Propriedades dos vidros utilizados na simulação computacional

Nota: Legenda:

\begin{tabular}{l|c|c|c}
\hline \multicolumn{1}{c|}{ Propriedade } & V20 & LowE & Lam \\
\hline Espessura total (mm) & 24 & 25 & 8 \\
Transmissão energética total (\%) (SHGC) & 0,481 & 0,629 & 0,602 \\
Transmissão luminosa (\%) & 0,505 & 0,721 & 0,570 \\
Transmitância térmica (W/m $\left.{ }^{2} \mathrm{~K}\right)$ & 2,708 & 1,949 & 6,144 \\
\hline
\end{tabular}

V20 = Vidro de controle solar convencional: duplo Silver 20 on Green $(6 \mathrm{~mm}$ na coloração verde, face externa/10 mm de câmara de ar/8 mm laminado incolor simples, face interna), da fabricante Guardian.

LowE = Vidro duplo low-e $25 \mathrm{~mm}$ (Double LoE Clear $6 \mathrm{~mm} / 13 \mathrm{Air}$ ), da biblioteca do software DesignBuilder. Lam = Vidro laminado de $8 \mathrm{~mm}$ de controle solar Silver 20 na coloração verde, da fabricante Guardian.

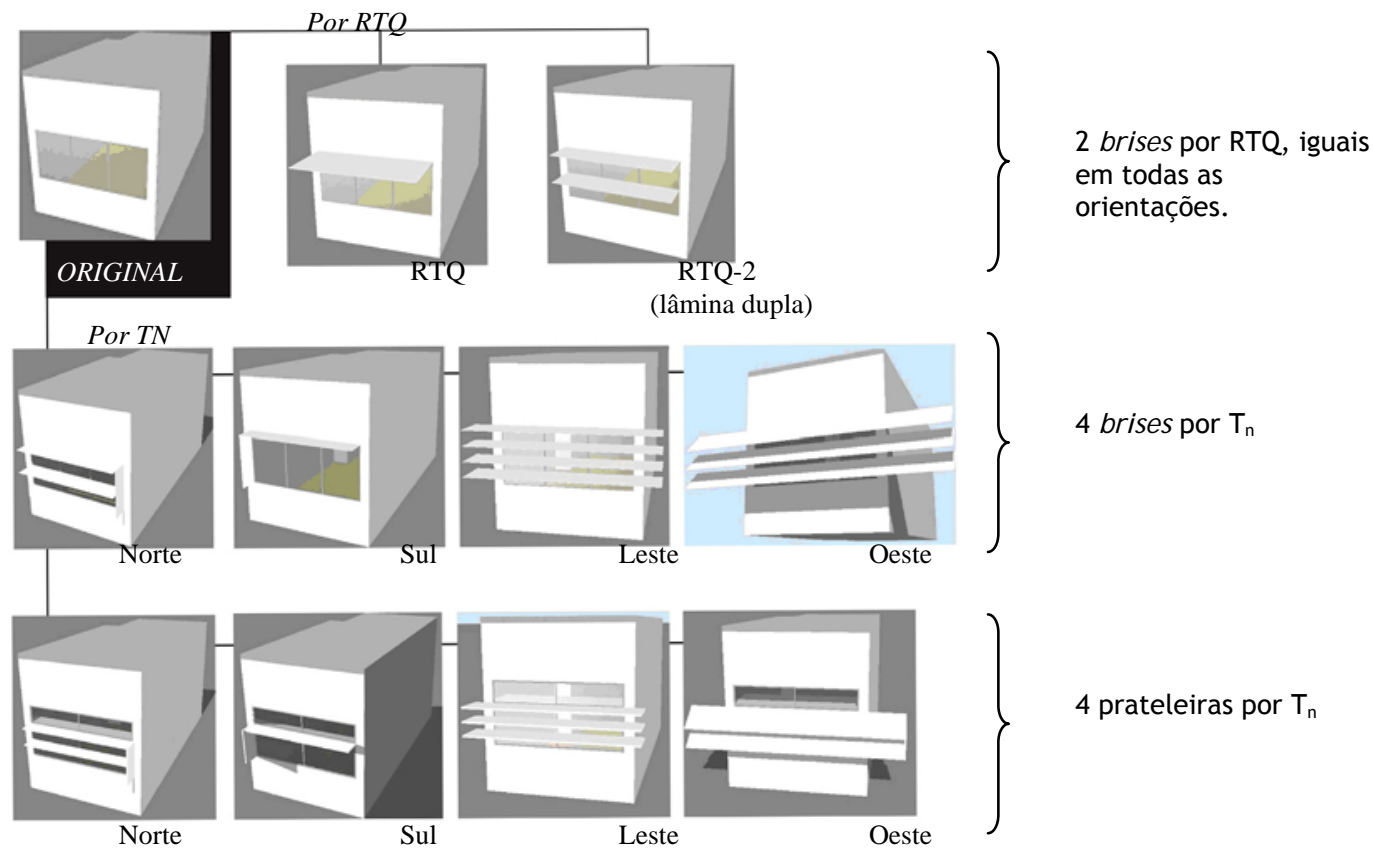

Figura 6 - Geometria de todas as proteções simuladas 
Como resultados da simulação do ambiente, foram obtidos dados de consumo de energia elétrica total, de consumo de energia elétrica devido à iluminação artificial e de ganho de calor pela fachada, em $\mathrm{kWh}$ ao ano. Tais saídas foram geradas por orientação solar (azimute $0^{\circ}, 90^{\circ}, 180^{\circ}$ e $270^{\circ}$ ), sendo depois convertidas em médias por protótipo para facilitar a comparação entre as proteções.

\section{Análise dos resultados}

A análise dos resultados foi feita em três partes: análise pelo método prescritivo, análise por simulação e, após essas análises, foram feitas comparações entre os métodos prescritivo e o de simulação.

\section{Avaliação de estudo de caso pelo método prescritivo do RTQ-C}

Os parâmetros utilizados na equação de ICenv (Equação 1) foram levantados do projeto original, sendo eles:

$$
\begin{aligned}
& \text { Ape = 8380,0 } \mathrm{m}^{2} ; \\
& \text { Atot }=136647,36 \mathrm{~m}^{2} ; \\
& \mathrm{FA}=0,06 ; \\
& \text { Aenv = 38771,8 } \mathrm{m}^{2} ; \\
& \mathrm{FF}=0,09 ; \\
& \text { PAFT=0,17; } \\
& \text { FS = 0,65; } \\
& \text { AVS = 0; e } \\
& \text { AHS =7,32. }
\end{aligned}
$$

Destaca-se que o AHS não é nulo por causa do autossombreamento do prédio, que foi contabilizado. Com tais dados aplicados nas Equações 1 e 2, obteve-se um Icenv de 34,72, com enquadramento da envoltória ao nível de eficiência “A” (Caso 1). Realizou-se então a análise paramétrica da Equação 1 para o edifício, substituindo os valores originais de AVS e AHS pelos ângulos $0^{\circ}, 10^{\circ}, 20^{\circ}, 30^{\circ}, 40^{\circ}, 50^{\circ}$. O ângulo $7,32^{\circ}$, devido ao autossombreamento do edifício, também foi incluído. Os resultados são mostrados na Tabela 3 e deram origem aos gráficos Ângulos $\mathrm{x}$ Indicador de Consumo apresentados.

Na Tabela 3 observa-se que as variações de AVS não influenciam na classificação da envoltória. $\mathrm{Ou}$ seja, a classificação seria sempre “A”, independentemente da existência e/ou das características de proteções horizontais sobre as aberturas, nessas condições avaliadas. Em contraponto, variações em AHS fazem a classificação mudar de "A" para "B" e deste para “C”. O nível "A” é obtido se o edifício não adotar qualquer tipo de proteção vertical. A partir da inserção de pequenos brises verticais, resultando num AHS médio entre $9,7^{\circ}$ e $49,3^{\circ}$, o nível do edifício é rebaixado para "B”. O nível " $C$ ” seria obtido a partir de $49,4^{\circ}$, mas destaca-se que essa situação não é possível, já que o RTQ-C limita o ângulo de sombreamento em $45^{\circ}$ para favorecer o aproveitamento da luz difusa, conforme exposto anteriormente. Como observado no gráfico correspondente, um aumento de AHS produz um aumento em ICenv, contradizendo a expectativa difundida de que proteções solares verticais reduzem o consumo de energia no clima e latitude locais. Se a equação do RTQ-C para a Zona Bioclimática 3 tiver sido gerada a partir de simulações em cidade de clima frio (Florianópolis) considerando calefação, supõe-se que o comportamento observado advenha do fato de que as proteções verticais provoquem o acionamento do sistema de calefação em uma cidade de clima frio no inverno, ao bloquearem ângulos solares baixos. Como em Belo Horizonte não é usada a calefação para aquecimento como prática de mercado, esse comportamento não seria observado. Entretanto, maiores estudos devem dedicar-se a esse tema.

Dessa análise percebe-se que o menor indicador de consumo é obtido quando AVS é o maior possível e, opostamente, quando AHS for o menor possível. Adotou-se então a combinação $\mathrm{AVS}=45^{\circ}$ e AHS $=0^{\circ}$ para compor a proteção ideal para o edifício. Com esses ângulos, portanto, foram dimensionados os dois brises por RTQ-C. Entende-se que tais ângulos, por definição do próprio RTQ-C, resultam da média ponderada de todas as aberturas de todas as fachadas do edifício. Mas, para este estudo admitiu-se que esses valores sejam aplicados diretamente sobre uma abertura.

Com esses novos ângulos aplicados nas Equações 1 e 2, obteve-se um ICenv de 20,51 com enquadramento da envoltória ainda no nível "A" (Caso 2). Essa classificação foi antecipada pela análise paramétrica. Salienta-se que o AHS aplicado foi equivalente a $7,32^{\circ}$ por causa do autossombreamento. De fato, se AHS $=0^{\circ}$ fosse aplicado, o $\mathrm{IC}_{\text {env }}$ seria igual a 18,86, mas a condição não representaria a realidade do edifício. 
Tabela 3 - Variações experimentadas em AHS e AVS e efeitos no indicador de consumo do TJ MG

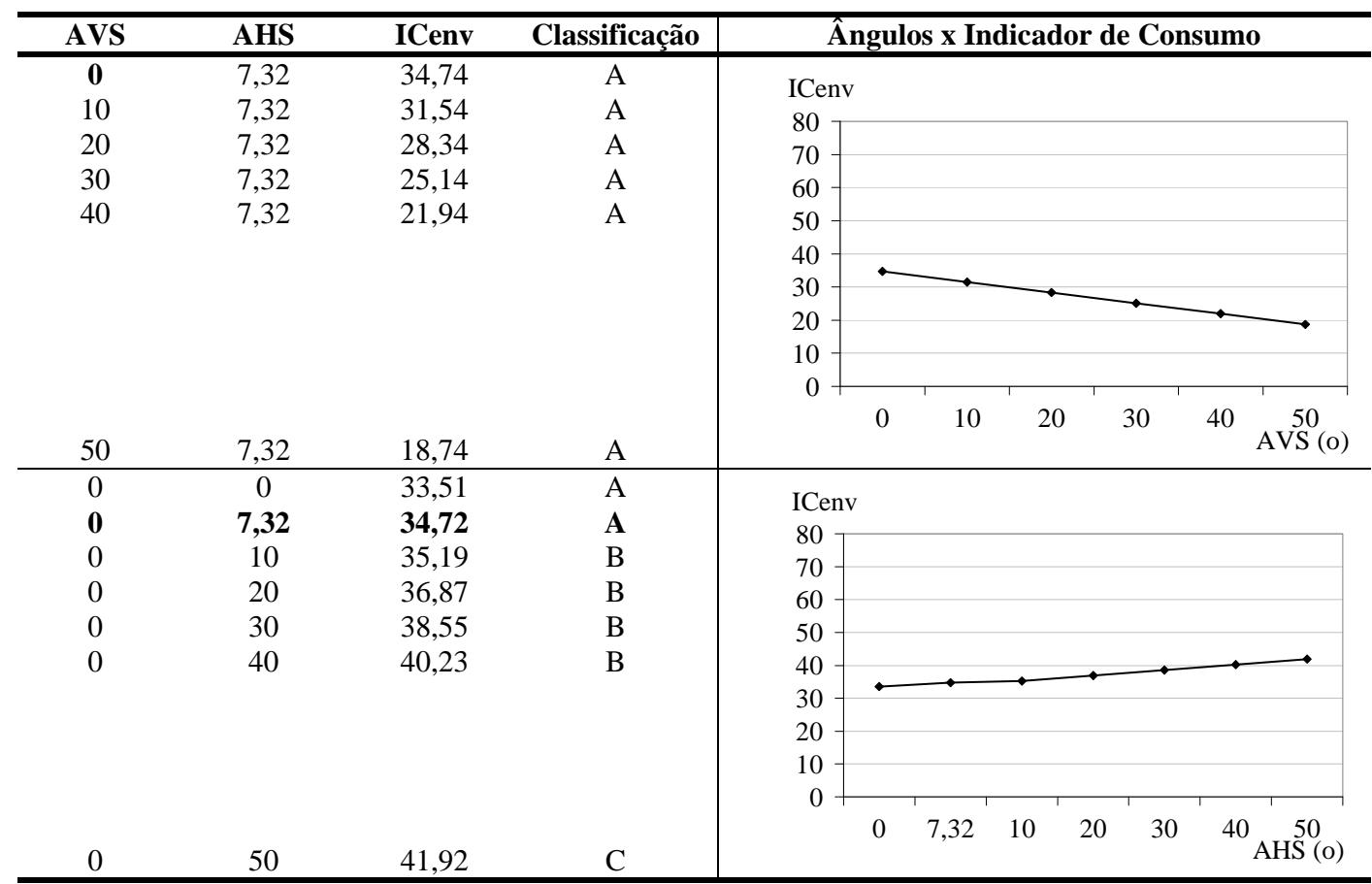

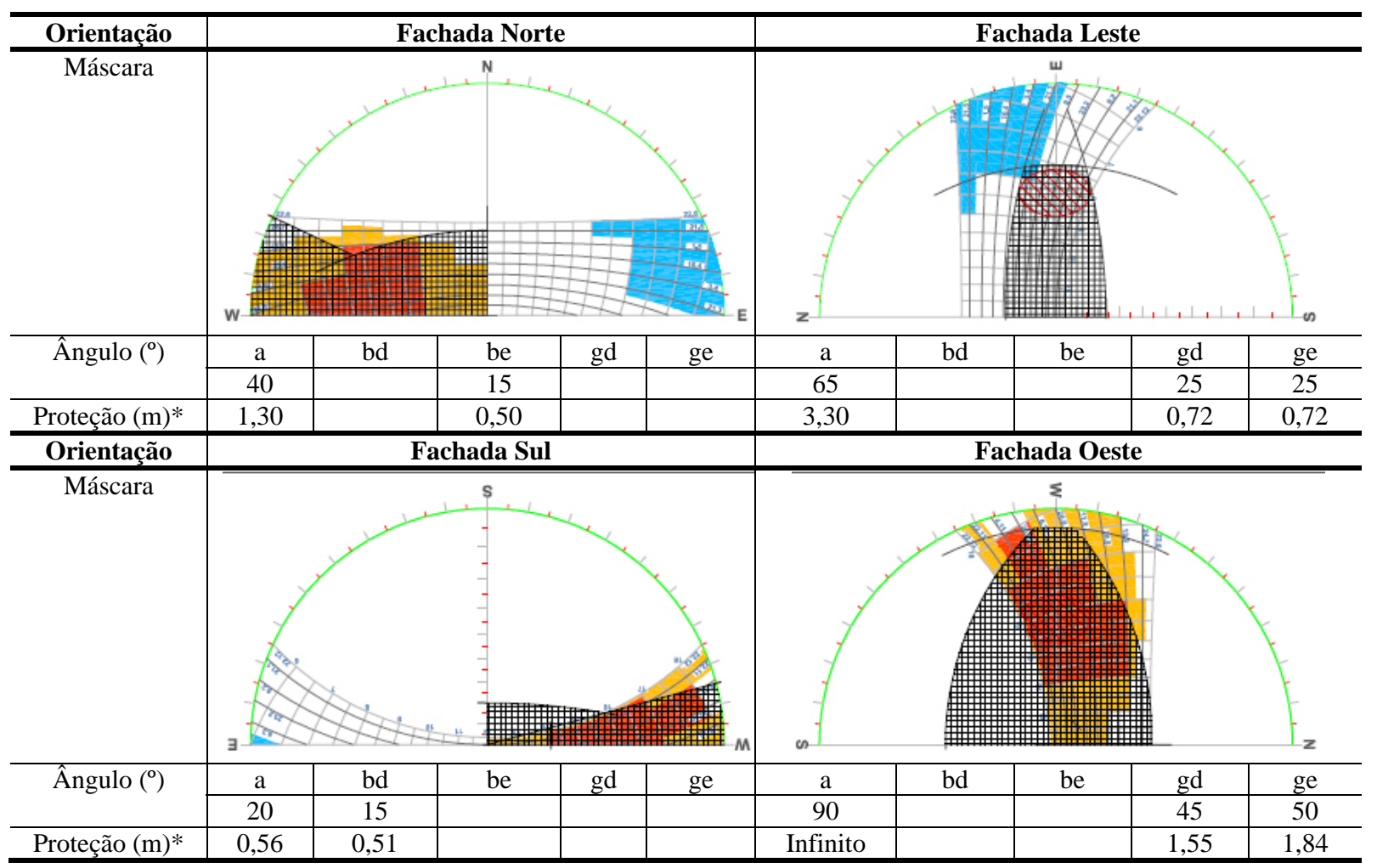

Figura 7 - Máscaras para definição de ângulos de sombreamento AVS e AHS e das respectivas dimensões das proteções segundo o método da Temperatura Neutra para as quatro orientações do edifício

Nota: *Dimensões das proteções foram estabelecidas considerando abertura de 1,65 x 3,95/1,05 m.

** Correção: a usado na fachada oeste $=90^{\circ}$; proteção total. 
Prosseguiu-se com o dimensionamento dos ângulos pela Temperatura Neutra. As máscaras de sombra com as quais se obtiveram os ângulos por $\mathrm{T}_{\mathrm{n}}$ são apresentadas na Figura 7. Considerando o tipo de clima e tamanho de abertura, as máscaras proporcionam sombreamento sobre a janela quando:

(a) a temperatura do ar exterior está no mínimo 3 ${ }^{\circ} \mathrm{C}$ acima da $\mathrm{T}_{\mathrm{n}}$ mensal; e/ou

(b) a temperatura do ar é no mínimo $2^{\circ} \mathrm{C}$ acima de $T_{n}$ e a radiação é maior que $600 \mathrm{~W} / \mathrm{m}$.

Aplicando-se esses ângulos às orientações correspondentes no edifício, obteve-se uma média de $\mathrm{AVS}=55,54^{\circ}$ e de AHS $=19,47$. Com eles, o ICenv reduziu-se para 18,51 (Caso 3).

Esse resultado não contradiz o cálculo de brise por RTQ, no qual foi mostrado que o ICenv mínimo possível para o TJMG é gerado pela combinação AVS $=45^{\circ}$, AHS $=7,32^{\circ}$. Explica-se o motivo: em $T_{n}$ foi feita a redução do percentual de área de abertura na fachada total (PAFt) do edifício, o que contribuiu para seu menor indicador entre todos os três casos avaliados. Quando a extensão da lâmina gerada pelo ângulo de $T_{n}$ resultou num tamanho excessivamente longo, a proteção foi redimensionada. A solução mais pratica foi a substituição de lâminas únicas por outras paralelas, menos longas. Essa substituição não afetou o PAFt porque a espessura de todas as lâminas foi considerada desprezível. Mas, a oeste foi necessário inclinar as chapas, o que obstruiu significativamente a área envidraçada e demandou recalculo do PAFt. Nota-se que a redução do valor do PAFt foi muito pequena, mas afetou ICenv de modo a demonstrar a sensibilidade da equação à variação desse parâmetro.

A Tabela 4 apresenta os valores encontrados de ICenv e a possibilidade de classificação de envoltória por ele permitida nos três casos analisados pelo RTQ-C. A depender de ICenv, a envoltória do edifício poderá alcançar o nível "A" nos três casos.

\section{Avaliação de estudo de caso por simulação computacional}

A seguir são feitas análises dos protótipos com proteção solar. Adotou-se para todas as proteções um material refletivo opaco de cor clara, com absortância de 0,20.

\section{Brises por RTQ-C}

A proteção solar do protótipo "RTQ" e do "RTQ2" possui os ângulos AVS $=45^{\circ}$ e AHS $=0^{\circ}$. Optouse por dimensionar o brise de RTQ a partir da geometria mais simples possível, a lâmina única, com 1,55 m sem afastamento relativo à abertura, perpendicular à fachada e fixa. O brise de RTQ-2 adota os mesmos ângulos, mas usa duas lâminas paralelas de 0,78 m de extensão cada. Em nenhum caso há extensão do brise à esquerda ou direita da abertura (não há ângulo gama).

As lâminas paralelas apresentaram desempenho melhor que a lâmina única (Tabela 5 e Gráfico 1). O consumo médio de energia de “RTQ- 2" é 4,6\% menor que o de "RTQ". Em relação ao protótipo sem proteção “Original”, "RTQ- 2" reduziu o consumo médio total em 12,9\%, e "RTQ", em $8,9 \%$. Essas foram as maiores reduções obtidas entre todas as proteções solares avaliadas neste trabalho.

O consumo médio com iluminação em "RTQ-C-2" é $27,4 \%$ inferior ao de "RTQ-C". Isso era esperado, visto que em "RTQ-C-2" a menor extensão da lâmina favorece a entrada de luz difusa, além de a lâmina inferior de cor clara refletir luz para o interior do ambiente.

Entretanto, RTQ-2 tem maior ganho anual de calor pela fachada: a menor extensão da lâmina piora a condição de sombreamento da fachada opaca, e a lâmina inferior aumenta o ganho de calor pelo vidro ao refletir radiação para o interior.

Considerando os resultados por orientação solar, há maior similaridade no consumo em “RTQ”. Na fachada sul, o uso de proteção aumentou o consumo total em relação à "Original”: acréscimo de $10 \%$ no caso de "RTQ" e de 3,8\% para "RTQ2 ". Isso reitera a necessidade de considerar-se a orientação da proteção nas análises energéticas. Nas demais orientações, houve redução do consumo total.

Tabela 4 - Valores dos parâmetros e classificações resultantes dos Casos 1, 2 e 3

\begin{tabular}{l|c|c|c|c|c}
\hline \multicolumn{1}{c|}{ Casos } & PAFt & $\begin{array}{c}\text { AVS } \\
\mathbf{(}^{\mathbf{o}} \mathbf{c}\end{array}$ & $\begin{array}{c}\text { AHS } \\
\mathbf{(}^{\mathbf{0}} \mathbf{)}\end{array}$ & ICenv & $\begin{array}{c}\text { Classificação } \\
\text { por ICenv. }\end{array}$ \\
\hline 1) Envoltória original & 0,17 & 0 & 7,32 & 34,72 & $\mathrm{~A}$ \\
2) Proteções por RTQ inseridas & 0,17 & 45 & 7,32 & 20,11 & $\mathrm{~A}$ \\
3) Proteções por $\mathrm{T}_{\mathrm{n}}$ inseridas & 0,16 & 55,54 & 19,47 & 18,51 & $\mathrm{~A}$ \\
\hline
\end{tabular}




\section{Brise “RTQ-2" x Brise $T_{n}$}

Quando se compara o brise de melhor desempenho dimensionado por RTQ, com lâmina dupla, e o brise dimensionado pela Temperatura Neutra para cada orientação solar, entende-se que o desempenho de "RTQ-2" é melhor em termos de consumo quando tomadas as médias de todas as fachadas.

Realmente, o consumo médio anual de energia de "RTQ-2" é 5,9\% inferior ao consumo de "Brise $\mathrm{T}_{\mathrm{n}}$ ”. Comparando-se os dados por fachada, tem-se que o consumo é sempre menor em "RTQ-2", exceto na fachada a sul. A maior diferença está na orientação oeste, condição na qual "RTQ-2" apresenta consumo com iluminação 210,4\% inferior ao de "Brise $\mathrm{T}_{\mathrm{n}}$ ”. Isso se deve fundamentalmente pelo brise inclinado de $T_{n}$ que obstrui o vidro nessa orientação. Por outro lado, acredita-se que o menor consumo com iluminação a oeste ocorre em "RTQ-C-2", que contribuiu tanto para que a média de consumo desse protótipo fosse inferior a de $T_{n}$, seja possível com certo desconforto dos ocupantes, sujeitos à penetração da radiação solar direta pela abertura na maior parte da tarde. O ganho médio de calor pelo vidro em "RTQ-C-2" é quase $40 \%$ maior que em "Brise $\mathrm{T}_{\mathrm{n}}$ ”, o que confirma que a proteção da abertura em "Brise $\mathrm{T}_{\mathrm{n}}$ ” é mais eficiente.

Nessa etapa aproveitou-se para avaliar se o consumo de energia diminui com a redução do AHS, conforme previsto na análise paramétrica de ICenv x AHS. Retiraram-se os brises verticais de "Brise $T_{n}$ ” nas orientações em que existiam: a sul e a norte. Como resultado da simulação, o consumo anual de energia diminuiu na fachada sul, e aumentou a norte. Ao final, a média de consumo total de "Brise $\mathrm{T}_{\mathrm{n}}$ - Sem vertical”, considerando-se as quatro orientações, aumentou $0,4 \%$. Como na orientação sul a placa vertical protege a abertura em horários de menor carga térmica da radiação, a carga acrescentada provavelmente não foi suficiente para aumentar o consumo com ar condicionado, enquanto a área de penetração de luz natural foi aumentada e reduziu o consumo de iluminação. A norte a radiação incidente fez aumentar o consumo de energia, e também houve redução do consumo com iluminação.

\section{Proteções por $T_{n}$ : Prateleiras de Luz}

Nesta seção, são avaliados os resultados das simulações das prateleiras de luz por $T_{n}$. Antes, porém, observa-se que houve alteração da abertura para instalação das prateleiras. A altura do peitoril da janela foi mantida em 105,0 cm (Figura 8). A janela foi dividida em duas pela prateleira instalada a $210,0 \mathrm{~cm}$ de altura, paralelamente ao piso. O segmento inferior ficou com $105,0 \mathrm{~cm}$ de altura. A janela superior foi limitada a $60,0 \mathrm{~cm}$, demandando a redução em $15 \mathrm{~cm}$ tanto da altura do fechamento opaco acima da proteção quanto do forro. Este ficou com 97,0 cm de altura, dimensão que não inviabiliza a passagem das instalações elétricas ou do ar condicionado especificado no projeto original. $\mathrm{O}$ material escolhido para as prateleiras tem as superfícies refletoras para um maior aproveitamento da luz natural.

Observa-se que na orientação oeste a dimensão interna da prateleira foi limitada em 150,00 cm, não sendo possível o bloqueio total da radiação direta a partir das $17 \mathrm{~h}$ no verão e das $16 \mathrm{~h}$ no inverno, aproximadamente.

Criaram-se três protótipos variando-se o tipo de vidro das aberturas. A "Prateleira - Controle Duplo” mantém o vidro duplo de controle solar convencional previsto em projeto. Este foi o mesmo vidro utilizado nas simulações do protótipo original e dos brises. Já em "Prateleira - Controle e Low-e”, permanece o vidro de controle solar na parte inferior e substituiu-se o vidro da janela superior pelo low-e, de maior transmissão luminosa. E em "Prateleira - Laminado" as duas aberturas recebem vidro laminado de controle solar convencional.

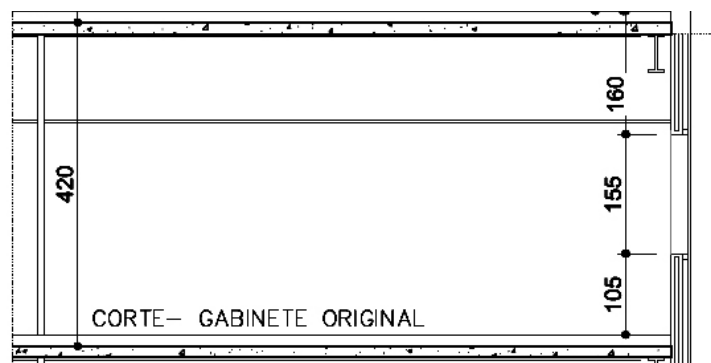

(a)

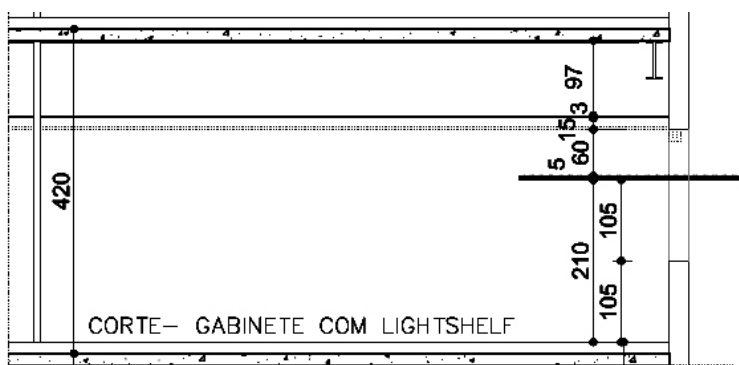

(b)

Figura 8 - Corte do ambiente em estudo mostrando em (a) o projeto original e em (b) as alterações que viabilizaram o uso de prateleira de luz (lightshelf)

Notas: dimensões verticais em cm e dimensões horizontais da prateleira são apenas ilustrativas.

Fonte: adaptado de TJMG/IDEAL (INSTITUTO..., 2009). 
As prateleiras com vidro de controle solar convencional aplicado nas duas aberturas tiveram melhor desempenho. $\mathrm{O}$ vidro duplo reduziu mais o consumo médio de energia total, e o laminado reduziu mais o consumo médio com iluminação.

O consumo médio total de energia de "PrateleiraControle e $L o w-e$ " é muito próximo de "Prateleira - Laminado". Já "Prateleira - Controle Duplo" apresentou um consumo médio cerca de 6,5\% inferior ao dos demais, demonstrando ser o mais eficiente dos três nesse aspecto.

As maiores diferenças estão no consumo com iluminação. O consumo médio de "Prateleira Laminado” é o menor, sendo 3,7\% inferior ao de "Prateleira - Controle e Low-e". O consumo médio com iluminação em "Prateleira - Controle Duplo" tem diferença de 46,6\% em relação a "Prateleira Laminado", com valor muito próximo ao obtido em "RTQ-2". Em todas as prateleiras a fachada norte é a de menor consumo, mas a sequência de orientações que se segue depende do tipo de vidro utilizado.

\section{Desempenho geral dos protótipos em relação a "Original"}

Quando as proteções solares foram inseridas em “Original”, houve reduções de até $12,9 \%$ no consumo médio total, percentual alcançado com “Brise RTQ-2” (Tabela 7 e Figura 9).

A redução no consumo total proporcionada pelo "Brise $\mathrm{T}_{\mathrm{n}}$ " foi de 7,8\%, valor equivalente ao da prateleira de luz com vidro duplo.

As prateleiras com vidro laminado e com vidro low-e proporcionaram reduções pouco significativas no consumo total de "Original", com valores inferiores a $2 \%$. Porém, foram as únicas proteções solares avaliadas que provocaram diminuição no consumo com iluminação em relação a "Original".

Pode-se estimar que, apesar de "RTQ-2" ter alcançado a maior redução no consumo médio total, "Prateleira - Laminado" apresenta melhor desempenho entre as proteções. Isso porque combina tanto a redução no consumo total quanto no de iluminação, devido ao tipo de vidro utilizado e ao dimensionamento das lâminas por $\mathrm{T}_{\mathrm{n}}$.

Tabela 5 - Dados médios anuais dos protótipos comparados ao de "Original"

\begin{tabular}{l|c|c|c|c|c|c}
\hline \multirow{2}{*}{\multicolumn{1}{c|}{ Protótipo }} & \multicolumn{3}{|c|}{ Variáveis } & \multicolumn{3}{c}{ Diferença sobre “Original” } \\
\cline { 2 - 7 } & Energia* & Iluminação & $\begin{array}{c}\text { Calor pela } \\
\text { fachada** }\end{array}$ & Energia & Iluminação & $\begin{array}{c}\text { Calor pela } \\
\text { fachada** }\end{array}$ \\
\cline { 2 - 7 } & $\mathbf{k W h} / \mathbf{m}^{\mathbf{2}}$ & $\mathbf{k W h} / \mathbf{m}^{2}$ & $\mathbf{k W h}$ & $\mathbf{\%}$ & $\mathbf{\%}$ & $\mathbf{\%}$ \\
\hline Original & 70,2 & 7,5 & 358,8 & $\mathbf{0 , 0}$ & $\mathbf{0 , 0}$ & $\mathbf{0 , 0}$ \\
Brise RTQ & 64,0 & 11,2 & 98,8 & $-8,9$ & 49,4 & $-72,5$ \\
Brise RTQ-2 & 61,2 & 8,8 & 121,5 & $-12,9$ & 17,3 & $-66,1$ \\
Brise TN & 64,7 & 13,8 & 3,3 & $-7,8$ & 85,2 & $-99,1$ \\
Prateleira (Controle Duplo) & 64,8 & 8,8 & 210,9 & $-7,8$ & 17,9 & $-41,2$ \\
Prateleira (Controle e Low-e) & 68,9 & 6,2 & 638,7 & $-1,9$ & $-16,6$ & 78,0 \\
Prateleira (Laminado) & 69,1 & 6,0 & 741,6 & $-1,5$ & $-19,6$ & 106,7 \\
Brise $\mathrm{T}_{\mathrm{n}}$ sem vertical & 65,0 & 12,2 & 194,1 & $-7,4$ & 63,8 & $-45,9$ \\
\hline
\end{tabular}

Nota: * Energia média total anual.

** Ganho de calor total pela fachada.

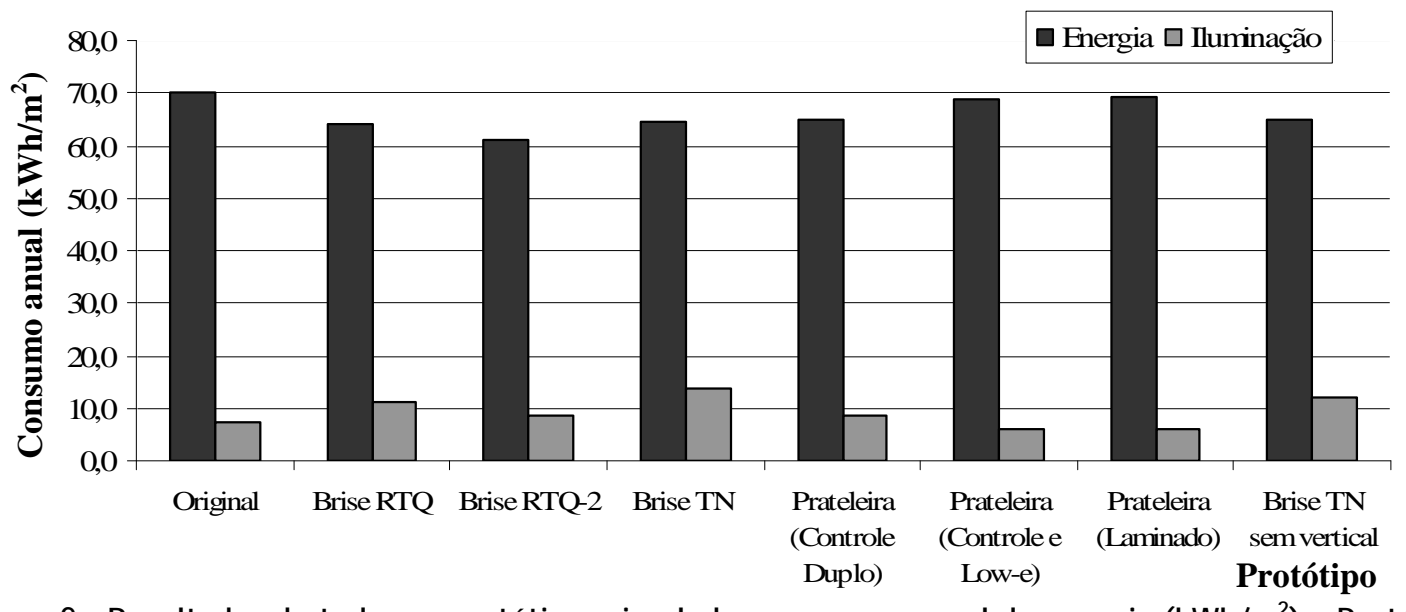

Figura 9 - Resultados de todos os protótipos simulados: consumo anual de energia $\left(\mathrm{kWh} / \mathrm{m}^{2}\right)$ x Protótipo 
Pode-se estimar que, apesar de "RTQ-2" ter alcançado a maior redução no consumo médio total, "Prateleira - Laminado" apresenta melhor desempenho entre as proteções. Isso porque combina tanto a redução no consumo total quanto no de iluminação, devido ao tipo de vidro utilizado e ao dimensionamento das lâminas por $\mathrm{T}_{\mathrm{n}}$.

A análise dos dados revela que nem sempre um menor ganho de calor total ou pela abertura implica menor consumo de energia. Por exemplo, o ganho de calor total de "Original” é quase a metade do de "Prateleira - Laminado", mas o consumo é um pouco maior, de $1,6 \%$, o que se atribui ao maior consumo com iluminação artificial.

Houve aumento de consumo com iluminação na fachada sul com a aplicação de todas as proteções analisadas em “Original”.

\section{Considerações finais}

Este estudo abordou o tema das proteções solares no contexto do "Regulamento Técnico da Qualidade para Eficiência Energética de Edifícios Comerciais, de Serviços e Públicos” (RTQ-C-C). O Regulamento foi aplicado em projeto real de edificação. Foi avaliada a influência de proteções solares na classificação da envoltória e no consumo de um de seus ambientes. Uma proposta de proteções solares calculadas pelo método da Temperatura Neutra foi aplicada, e seus efeitos no consumo foram avaliados. Também foi comparado o desempenho de brises e de prateleiras de luz com vidros diversos. O trabalho baseou-se no uso do método prescritivo do documento e em simulação computacional com os programas EnergyPlus e DesignBuilder.

Pela equação de indicador de consumo ( $\left.\mathrm{IC}_{\text {env }}\right)$ para o edifício, a classificação da envoltória alcança o nível máximo no RTQ-C, “A”.

Na simulação verificou-se que o consumo do ambiente foi reduzido em até 12,9\% com a instalação de proteções horizontais (brises) sobre a abertura. Esse percentual é resultado da média de consumo das quatro orientações de fachada a qual o protótipo foi submetido. Se o consumo for observado por orientação, as reduções são ainda maiores. Porém, pela equação de ICenv, a classificação da envoltória do edifício em nada é alterada pela existência de proteção horizontal para a edificação.

A equação de ICenv para essa zona também indica que o uso de brises verticais aumentaria o consumo do edifício, contradizendo a concepção usual de projetistas segundo a qual o uso desse tipo de proteção ajudaria a reduzir o consumo nesse local em qualquer orientação. A previsão de ICenv, em parte, converge com os resultados da simulação. Em um protótipo orientado a sul, retirando-se o brise vertical, o consumo reduziu-se. No mesmo protótipo, porém orientado a norte, essa retirada fez o consumo aumentar. Na avaliação final pela média dos resultados, como o aumento a norte foi muito superior em relação à redução a sul, tem-se que o consumo geral do protótipo aumentou com a retirada dos brises. Esses resultados reforçam a importância de considerar-se a orientação da fachada em análises de consumo. De qualquer modo, esse tema da redução de AHS merece estudos complementares, nos quais sejam experimentadas mais variações em fatores como dimensões das proteções, orientações de fachada, condições de clima e latitude.

O RTQ-C prescritivo da envoltória considera apenas o ângulo da proteção solar na avaliação. As simulações realizadas confirmaram a importância de outros fatores no desempenho energético, como a geometria das proteções solares, ao evidenciar as diferenças no consumo provocadas por proteções diferentes de um mesmo conjunto de ângulos.

Segundo o RTQ-C prescritivo, o ambiente analisado cumpre o requisito de aproveitamento da luz natural ao especificar o acionamento independente da fileira de luminárias próximo à janela. No entanto, como demonstrado, esse aproveitamento pode ser otimizado. As prateleiras de luz melhoram esse aproveitamento e reduzem o consumo com iluminação, especialmente quando associadas aos tipos de vidros de alta transmissão luminosa.

Concordando com a equação do RTQ-C, na simulação os brises gerados pela combinação de ângulos que gera um ICenv mínimo tiveram um consumo inferior ao dos brises definidos pelo método da Temperatura Neutra. Todavia, esse resultado converge se forem tomados os resultados médios, e não por orientação. Lembra-se que o método da Temperatura Neutra, além do interesse na redução do consumo de energia, leva em conta aspectos de conforto térmico e visual do usuário que não são avaliados diretamente pelo RTQ-C.

Como resultado importante, a simulação comprovou que o método de $\mathrm{T}_{\mathrm{n}}$ é eficiente na redução da incidência de radiação solar direta sobre a abertura.

Ao final, fazem-se algumas considerações. Pondera-se que o potencial de aproveitamento de luz natural pode ter sido superestimado neste trabalho, porque foi relacionado a um controle por dimerização contínua. Novas simulações nas quais sejam configurados outros tipos de dimerização, através de software específico de iluminação 
natural, esclareceriam melhor esse potencial. Lembra-se também que os resultados percentuais apresentados neste estudo devem ser tomados com cuidado, pois dependem da configuração dos protótipos, assim como das propriedades dos elementos construtivos e das cargas internas. Entende-se que futuras analises do RTQ- C e simulações relativas ao tema devem incluir a interferência do ocupante, o que é relevante para representar melhor a dinâmica de consumo de energia no ambiente.

\section{Referências}

ASSOCIAÇÃO BRASILEIRA DE NORMAS TÉCNICAS. NBR 5413: iluminância de interiores. Rio de Janeiro, 1992.

\section{ASSOCIAÇÃO BRASILEIRA DE NORMAS} TÉCNICAS. NBR 15220-3: desempenho térmico de edificações - parte 3: zoneamento bioclimático brasileiro e diretrizes construtivas para habitações unifamiliares de interesse social. Rio de Janeiro, 2005.

BRASIL. Ministério da Agricultura e Reforma Agrária. Departamento Nacional de Meteorologia. Normais Climatológicas 1961-1990. Brasília, 1992. 84 p.

BRASIL. Ministério de Minas e Energia. Eletrobrás. Procel Edifica. Pesquisa de Posse de Equipamentos e Hábitos de Uso (Ano-Base 2005): classe comercial alta tensão: relatório Brasil. 2008a. Disponível em:

$<$ http://www.eletrobras.com/>. Acesso em: 12 mar. 2009.

BRASIL. Ministério de Minas e Energia. Eletrobrás. Manual de Uso da "Regulamentação Para Etiquetagem Voluntária de Nível de Eficiência Energética de Edifícios Comerciais, de Serviços e Públicos”. Versão eletrônica 4. 2008. [mensagem pessoal, 26 jan. 2009]. 2008b.

BRASIL. Ministério do Desenvolvimento, Indústria e Comércio Exterior. Instituto Nacional de Metrologia, Normalização e Qualidade Industrial. Portaria INMETRO no 372: aprova o Regulamento Técnico da Qualidade para Eficiência Energética de Edifícios Comerciais, de Serviços e Públicos. 17 de setembro de 2010. 2010. Disponível em:

$<$ http://www.inmetro.gov.br/legislacao/detalhe.asp ?seq_classe $=1 \&$ seq_ato $=1462>$. Acesso em: 5 set. 2011.
BRASIL. Ministério do Desenvolvimento, Indústria e Comércio Exterior. Instituto Nacional de Metrologia, Normalização e Qualidade Industrial. Portaria INMETRO n 449: aprova o Regulamento Técnico da Qualidade para Eficiência Energética de Edificações Residenciais. 25 de novembro de 2010b. Disponível em: $<$ http://www.inmetro.gov.br/consumidor/produtos PBE/regulamentos/RTAC001627.pdf $>$. Acesso em 10 out. 2011.

CARLO, J. C. Desenvolvimento de Metodologia de Avaliação da Eficiência Energética do Envoltório de Edificações Não-Residenciais. Florianópolis, 2008. Tese (Doutorado em Engenharia Civil) - Programa de Pós-graduação em Engenharia Civil, Universidade Federal de Santa Catarina, Florianópolis, 2008.

GUTIERREZ, G. C. R.; LABAKI, L. C. Avaliação de Desempenho Térmico de Dispositivos de Proteção Solar. In: ENCONTRO NACIONAL SOBRE CONFORTO NO AMBIENTE CONSTRUÍDO, 7.; CONFERÊNCIA LATINOAMERICANA SOBRE CONFORTO E DESEMPENHO ENERGÉTICO DE EDIFICAÇÕES, 3., Curitiba, 2003. Anais... Curitiba: ANTAC, 2003.

\section{INSTITUTO PARA O DESENVOLVIMENTO} DE ENERGIAS ALTERNATIVAS NA AMERICA LATINA. Concurso Nacional de Monografias Energias Renováveis e Eficiência Energética: trabalhos selecionados. Florianópolis: IDEAL, 2009. Eco-Lógicas: renovar é pensar diferente.

MACEDO, C. C.; PEREIRA, F. O. R. Thermal and Luminous Performance of Direct Sunlighting Systems. In: PASSIVE AND LOW ENERGY ARCHITECTURE- PLEA, Santiago, 2003. Anais... Santiago, 2003.

PEREIRA, I. M.; SOUZA, R. V. G. Proteção Solar em Edificações Residenciais e Comerciais:

Desenvolvimento de Metodologia. In: ENCONTRO NACIONAL DE TECNOLOGIA DO AMBIENTE CONSTRUÍDO- ENTAC, 12, Fortaleza, 2008. Anais... Fortaleza: ANTAC, 2008.

SANTANA, M. V. Influência de Parâmetros Construtivos no Consumo de Energia de Edifícios de Escritório Localizados em Florianópolis, SC. Florianópolis, 2006. Dissertação (Mestrado em Engenharia Civil) Programa de Pós-graduação em Engenharia Civil, Universidade Federal de Santa Catarina, Florianópolis, 2006. 
SANTOS, C. M.; BASTOS, L. E. G. Influência dos Elementos de Fachada no Desempenho da Iluminação Natural em Edifícios de Escritórios de Planta Livre. In: ENCONTRO NACIONAL DE TECNOLOGIA DO AMBIENTE CONSTRUÍDO- ENTAC, 12., Fortaleza, 2008. Anais... Fortaleza: ANTAC, 2008.
SIGNOR, R. Análise de Regressão do Consumo de Energia Elétrica Frente a Variáveis Arquitetônicas Para Edifícios Comerciais Climatizados em 14 Capitais Brasileiras. Florianópolis, 1999. Dissertação (Mestrado em Engenharia Civil) - Programa de Pós-graduação em Engenharia Civil, Universidade Federal de Santa Catarina, Florianópolis, 1999.

Revista Ambiente Construído

Associação Nacional de Tecnologia do Ambiente Construído

Av. Osvaldo Aranha, $99-3^{\circ}$ andar, Centro

Porto Alegre - RS - Brasil

CEP $90035-190$

Telefone: +55 (51) 3308-4084

Fax: +55 (51) 3308-4054

www.seer.ufrgs.br/ambienteconstruido

E-mail: ambienteconstruido@ufrgs.br 